\title{
Critical Investigation of Heat Transfer in Oil Cooled Transformer
}

\author{
Dr. Ajoy Kumar \\ Principal, Chhatrapati Shivaji Maharaj Institute of Technology, Panvel, University of Mumbai, India
}

\begin{abstract}
Power transformer represents the largest portion of capital investment in transmission and distribution substations. Transformer functional life is influenced by thermal, mechanical and dielectricstresses. The concept of insulation 'Thermal life 'is a useful one, in which it can set a standard level of physical condition below which insulation integrity may be prejudiced by mechanical or dielectric stresses, normally experienced in service. In power transformer, the oil serves a dual purpose as insulating and cooling medium. The heat generated in the transformer is removed by its oil surrounding the source and is transmitted either to atmospheric air or water. Thermal modeling of power transformer top-oil considering viscosity and conductivity and other relevant parameters have been taken into account in the present work and accordingly an important correlation has been derived for ONAF (oil natural air forced) type of cooling. Result shows that the transformer top oil temperature varies remarkably with respect to time.However,within the range of the data covered the plotted figures show that rapid increase in the temperature of the transformer top oil could be achieved with increasing values of time after a certain period of time.
\end{abstract}

Keywords: ONAF, ONAN, OFAF, TOBS, Thermal modeling

\author{
List of symbols and abbreviations \\ A - Area \\ C - A constant \\ Ce - Electrical capacitance \\ $\mathrm{C}_{1}$ - A constant \\ $\mathrm{C}_{\mathrm{p}}$ - Specific heat of fluid \\ $\mathrm{C}_{\text {th }}$ - Thermal capacitance \\ $\mathrm{C}_{\text {th-oil- }}$ Equivalent thermal capacitance of the transformer oil \\ $\mathrm{C}_{\text {th-oil,rated }}$ - Rated equivalent thermal capacitance of the \\ transformer oil \\ $\mathrm{C}_{\text {wdn }}$ - Thermal capacitance of the winding \\ g - Gravitational constant \\ $\mathrm{g}_{\mathrm{r}}$ - Rated average winding to average oil temperature \\ gradient \\ Gr- Grashof number \\ W- Watt \\ $\rho$ - Oil density \\ $\beta$ - Coefficient of thermal cubic expansion of the oil \\ $\mu$ - Oil viscosity \\ $\mu_{\mathrm{pu}}$ - Oil viscosity per unit value \\ $v$ - kinematic viscosity of oil \\ $\theta$ - Temperature \\ $\theta_{\text {amb }}$ - Ambient temperature \\ $\theta_{\text {oil }}$ - Top-oil temperature \\ $\theta_{\text {hs }}$ - Hot-spot temperature \\ $\Delta \theta_{\text {oil,rated }}$ Rated top-oil temperature rise over ambient \\ $\Delta \theta_{\text {hs,rated }}$ - Rated hot-spot temperature rise over top-oil \\ $\tau_{\text {oil }}$-oil time constant \\ $\tau_{\mathrm{wdg}}$ - Winding time constant \\ $\tau_{\text {oil,rated }}$ - Rated top-oil time constant
}

h - Heat transfer coefficient

$\mathrm{H}$ - Hot-spot factor

i - Electrical current

I - Load current

$I_{\text {rated- Rated load current }}$

$\mathrm{k}$ - Oil thermal conductivity

$\mathrm{kg}$ - Kilogram

K- Load factor

L - A characteristic dimension length, width or diameter

$\mathrm{n}$ - A constant

$\mathrm{N}_{\mathrm{u}}$ - Nusselt number

$\mathrm{P}_{\mathrm{r}}$ - Prandtle number

q - Heat generation

$\mathrm{q}_{\text {tot }}$ - Heat generated by total losses

$\mathrm{q}_{\mathrm{fe}}$ Heat generated by no-load losses

$\mathrm{q}_{1}$ - Heat generated by load losses

R- Ratio of load losses at rated current to no-load losses

$\mathrm{R}_{\text {th-oil- Non-linear thermal resistance of the oil }}$

$\mathrm{R}_{\text {th-hs-oil }}$ - Non-linear winding to oil thermal resistance

$\mathrm{R}_{\text {th-wdn }}$ - Winding thermal resistance

$\mathrm{R}_{\text {th-insul }}$ - Winding insulation thermal resistance

\section{Introduction}

Transformer oil is expected to function as an insulating medium and heat transfer agent. The behavior of oil can be related to its molecular composition and its physical properties. The electrical properties and thermal behavior are the fundamental requirement of transformer oil. Oxidation is the primary cause of the degradation of the oil. The transformer oil manufacturers desire to supply the customer with oil that gives required and long performance in actual field operation. To achieve this objectives manufacturer's procedure the best base oil, undertake complicated refining operation and carry out extensive $R \& D$ to match different properties of oil at its molecular level to its actual field performance. The manufactures are responsible to establish the basis of the design of the insulating liquid for its intended end use[1].The electrical and heat transfer of properties of transformer oil are effected due to its oxidation, which degraded the oil in service[2]. With the production of oxidative copmponets, the heat transfer properties of the oil 


\section{International Journal of Science and Research (IJSR) \\ ISSN (Online): 2319-7064}

Index Copernicus Value (2015): 78.96 | Impact Factor (2015): 6.391

are affected, resulting in increase of transformer oil temperature, which give rise to more oxidation. Sometines, electrical stress also cause increase in the temperature of the transformer oil.

\subsection{Structural Analysis of Oil}

Liquid chromatographic studies [3] indicated that there is no difference between various types of oil with respect to the poly aromatic contents. Oxidative and aging behavior of transformer oil. The protection against the oxidation and aging is a factor related only to the amount and the type of aromatic compound present in transformer and available in oxygen $[4,5]$.No difference was found in the behavior of oil that could be related to their molecular composition.

\subsubsection{Oil properties}

Insulting oil forms a very significant part of the transformer insulating system and has the important functions of acting as an electrical insulation as well as a coolant to dissipate heat losses. The basic raw material for the production of transformer oil is a low viscosity lube termed as transformer oil base stock (TOBS)which is normally obtained by fractional distillation and subsequent treatment of crude petroleum. Important characteristics of TOBS must be kept within permissible limits in order to produce good insulating oils.TOBS is further refined by acid treatment process to yield transformer oil[6, 7$]$.

\section{Objective of the Present work}

Transformers are static electrical machines used for transmission and distribution of power at different voltages. In transformer two separate sets of coils (primary and secondary windings) are linked with the same magnetic flux (being wound on the same laminated iron core). The current density in winding is limited by local heating. The heat generated (copper loss and iron loss)is dissipated to environment. The local heating due to current density beyond permissible limit may cause temperature rise excessively high to further increasing the loss and ultimately damaging insulation. The permissible current density in different types of commercial transformers ranges from 900 amp/inch ${ }^{2}$ to $2600 \mathrm{amp}$ inch $^{2}$ [8].In order to increase the permissible current density, decrease the losses, protect the insulation there is need of cooling of transformer.

Attempts [9] has been made to estimate the temperature rise in transformer and heat transfer coefficient. The empirical relations are used as guidelines in design of transformers [8, 10 , and 11].

In the present work, investigation has been made in the heat transfer phenomena for oil cooled transformers while its design for the objective of:

1) To investigate heat transfer coefficient Vs heat flux data.
2) To investigate the effect of transformer oil grade and temperature on heat transfer coefficient.

3) To find correlation to be used in thermal design of transformer.

4) Prediction of thermal equilibrium on the basis of predicted heat transfer coefficient in a transformer.

5) Actual testing of transformer.

6) To investigate the discrepancies in the model/correction selected and correlation for heat transfer.

\section{Thermal Design of Transformer Considering Heat Transfer Effect}

A power transformer is a static piece of apparatus with two or more winding which by electromagnetic induction, transformers a system of alternating voltage and current into system of voltage usually of different values and at same frequency or the purpose of transmitting electrical power [12].The IEC354 loading guide for all oil immersed power transformer [13] and IEI guide for loading mineraloil immersed transformer [14] indicate that low oilimmersed transformer can be operated in different ambient conditions and load levels without exceeding the acceptable detoriation limit of insulation due to the thermal reason. According to the loading guides the hot spot temperature in a transformer widely consists of three components viz. the ambient temperature rise, the top oil temperature rise and the hot temperature riseover the top oil temperature. The variation of top oil temperature is described by an exponential equation based on a time constant. The top oil time constants suggested by IEC loading guide is 150 minutes for oil natural air natural cooling mode (ONAN).

By analyzing the measured results of tested power transformers, it was noticed that the hot spot temperature rise over top oil temperature at load changes is a function depending on time as well as the transformer loading. It was also noticed that the top oil temperature constant is shorter than the time constant suggested by the present loading guide especially for the ONAN and ONAF cooling modes.

The present research work is aimed to develop a generalized model. This work presents a new temperature calculation method based on heat transfer theory.

\section{Top oil Temperature Model}

The top oil temperature has been given as thermal circuit(shown in Fig.1) based on the thermal electrical analogy and heat transfer theory[15,16].The heat generated by both no load and load transformer losses is represented by two ideal heat sources [15].The ambient temperature is represented as an ideal temperature source. 


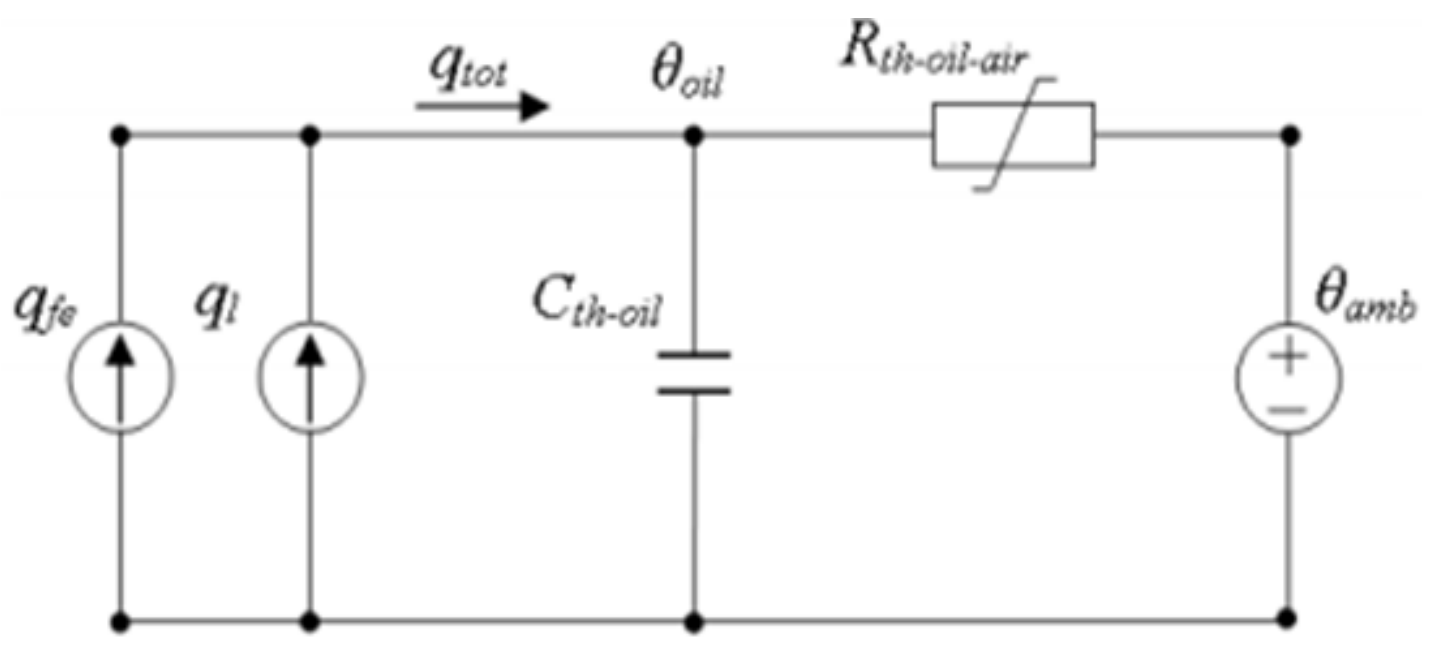

Figure 1: Top Oil temperature model

The nonlinear oil thermal resistance $\mathrm{R}_{\text {th-oil }}$ according to heat transfer theory [16] is given by the following equation

$$
\mathrm{R}_{\text {th-oil }}=\frac{1}{h \cdot A}
$$

Based on heat transfer theory the natural convention oil flow around vertical, inclined and horizontal plates and cylinders can be described by the empirical co-relation $[13,17,18,19$, and 20]:

$$
\mathrm{N}_{\mathrm{u}}=\mathrm{C} \cdot\left[\mathrm{G}_{\mathrm{r}} \cdot \mathrm{P}_{\mathrm{r}}\right]^{\mathrm{n}}
$$

Where $\mathrm{C}$ and $\mathrm{n}$ are constants dependent on whether the oil circulation is laminar or turbulent.

The Nusselt number $\left(\mathrm{N}_{\mathrm{u}}\right)$, Prandtle number $\left(\mathrm{P}_{\mathrm{r}}\right)$, and Grashofnumber $\left(G_{r}\right)$ are described by the following equations, respectively.

$$
\begin{gathered}
\mathrm{N}_{\mathrm{u}}=\frac{h \cdot l}{K} \\
\mathrm{P}_{\mathrm{r}}=\frac{C_{p} \cdot \mu}{K} \\
\mathrm{G}_{\mathrm{r}}=\frac{L^{3} \cdot \rho^{2} \cdot g \cdot \beta \cdot(\Delta \boldsymbol{\theta o o i l})}{\mu 2}
\end{gathered}
$$

By substituting (3), (4), (5) into (2) we get

$$
\frac{h \cdot l}{K}=\mathrm{C} \cdot\left[\frac{L^{3} \cdot \rho^{2} \cdot g \cdot \beta \cdot(\Delta \boldsymbol{\theta o o i l})}{\mu 2} \cdot \frac{C_{p} \cdot \mu}{K}\right]^{\mathrm{n}}
$$

The variation of viscosity with temperature is much higher than the variation of other oil physical parameters and thermal conductivity that depends on temperature.

The ratio of load losses at rated current to no load loss

$$
\mathrm{R}=\frac{q_{c u}}{q_{f e}}
$$

and the load factor $\mathrm{k}$ :

$$
\mathrm{K}=\frac{I}{I_{\text {rated }}}
$$

Where, $I$ is the load current and $I_{\text {rated }}$ is the rated current.

Based on the heat transfer criteria the final equation has been derived as:

$$
\begin{array}{r}
\frac{1+R \cdot K^{2}}{1+R} \cdot \mu_{p u}^{n} \cdot \Delta \boldsymbol{\theta}_{\text {oil } l_{\text {rated }}} \cdot \boldsymbol{K}_{\boldsymbol{p u}}^{\boldsymbol{n}-\mathbf{1}} \\
=\boldsymbol{K}_{\boldsymbol{p} \boldsymbol{u}}^{\boldsymbol{n}-\mathbf{1}} \cdot \mu_{p u}^{n} \cdot \tau_{\text {oil_rated }} \cdot \frac{\mathrm{d} \boldsymbol{\theta o i l}}{\mathrm{dt}} \\
+\frac{(\boldsymbol{\theta o i l}-\boldsymbol{\theta a m b})^{1+n}}{\Delta \boldsymbol{\theta}_{\text {oil_rated }}^{n}}
\end{array}
$$

The above thermal model equation has been taken into account for oil viscosity and thermal conductivity. This has been utilized to work out the values of temperature at different time intervals by substituting the values of relevant input data.Fig. 2 has been plotted on top oil temperature $\mathrm{v} / \mathrm{s}$ time for 400 MVA ONAF cooling. Similarly Fig. 3 represents the top oil temperature $\mathrm{v} / \mathrm{s}$ time for $80 \mathrm{MVA}$ ONAF cooling. Fig. 4 represents the top oil temperature $\mathrm{v} / \mathrm{s}$ time for 605 MVA ONAF cooling. 

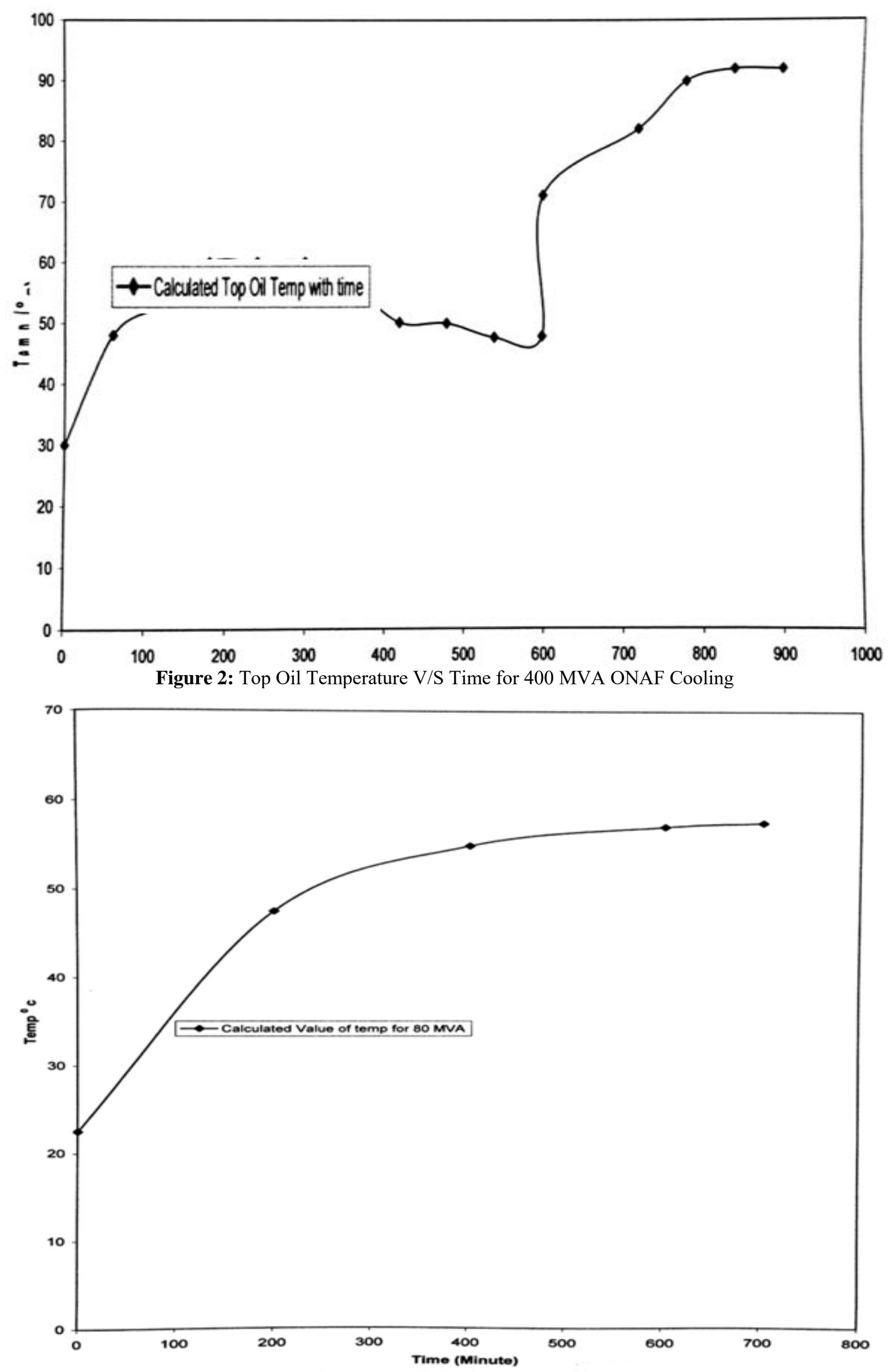

Figure 3: Top Oil Temperature V/S Time for 80 MVA ONAF Cooling

Volume 6 Issue 1, January 2017 www.ijsr.net 


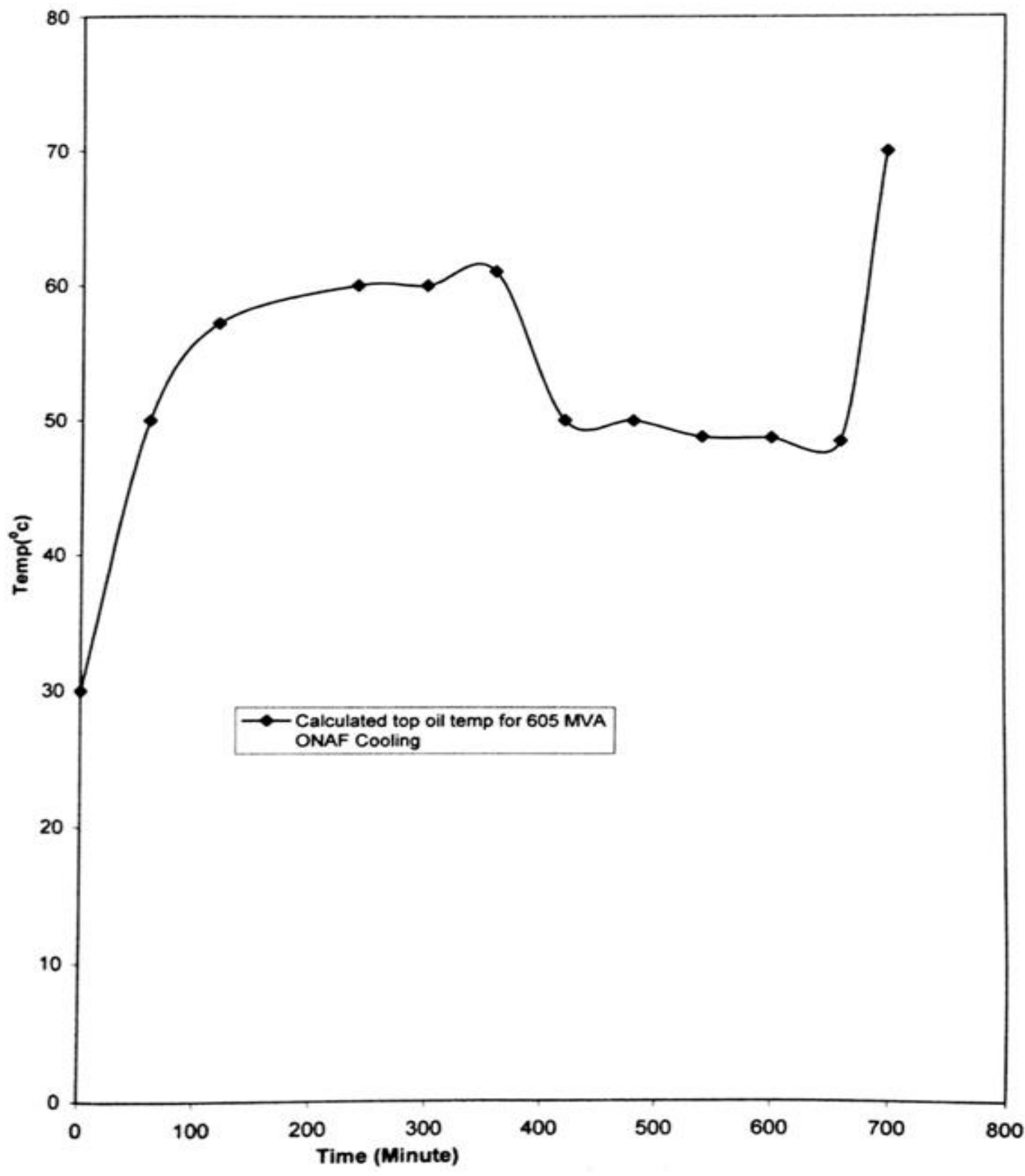

Figure 4: Top Oil Temperature V/S Time for 605 MVA ONAF Cooling

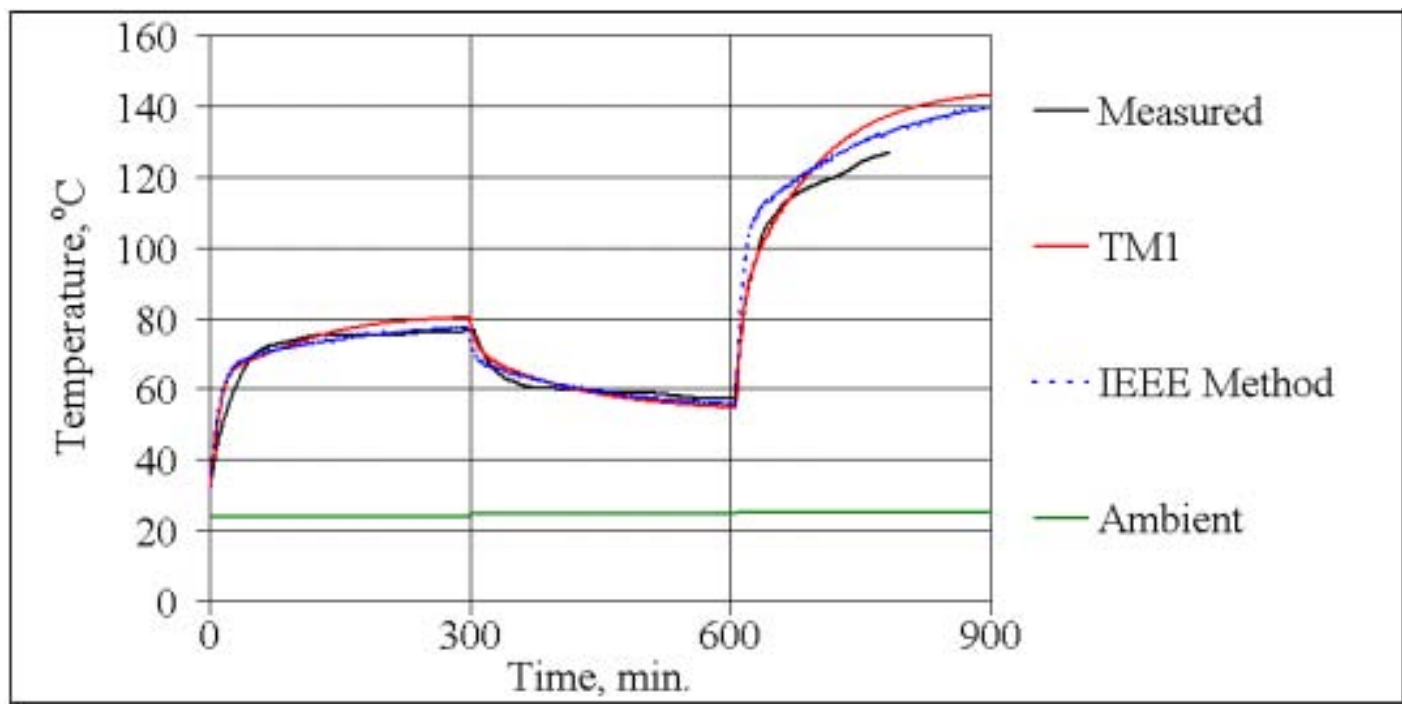

Figure 4: The hot-spot temperature of the $410 \mathrm{kV}$ winding in the $400 \mathrm{MVA}$ ONAF transformer

Volume 6 Issue 1, January 2017

www.ijsr.net 
International Journal of Science and Research (IJSR)

ISSN (Online): 2319-7064

Index Copernicus Value (2015): 78.96 | Impact Factor (2015): 6.391

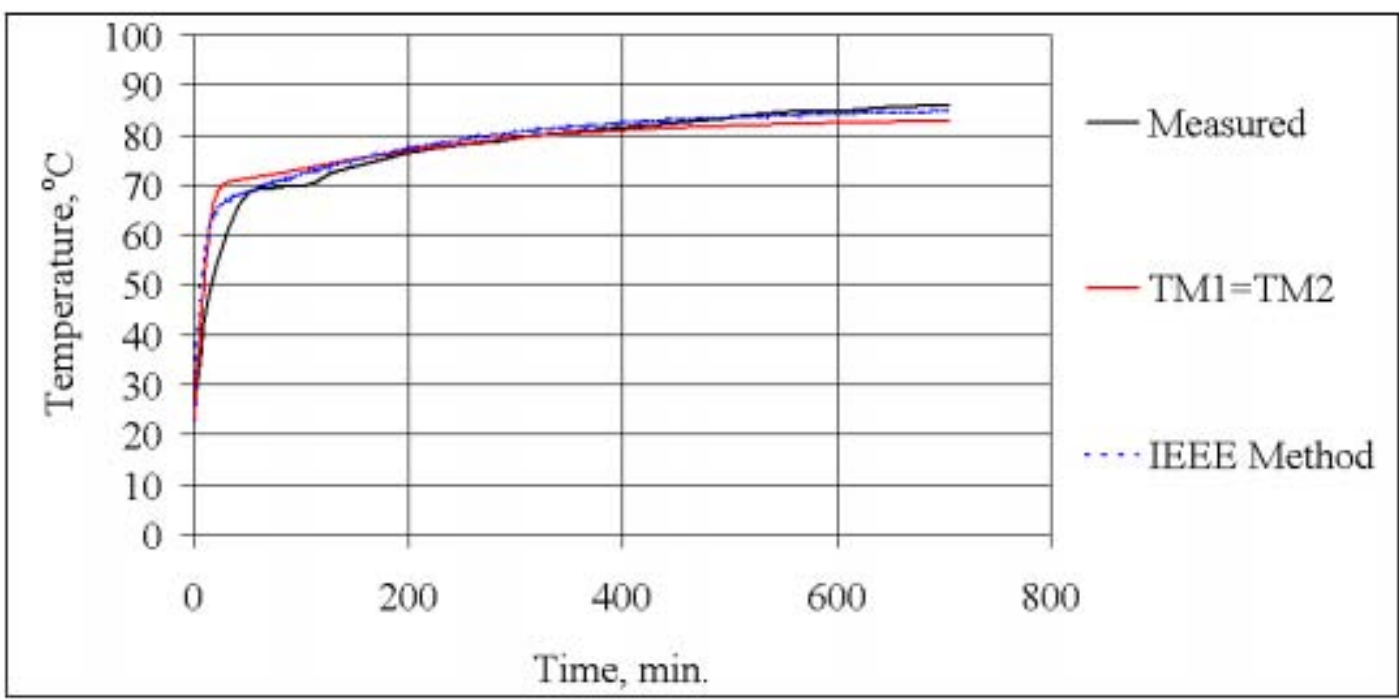

Figure 5: The hot-spot temperature of the $400 \mathrm{kV}$ winding in the $80 \mathrm{MVA}$ ONAN transformer

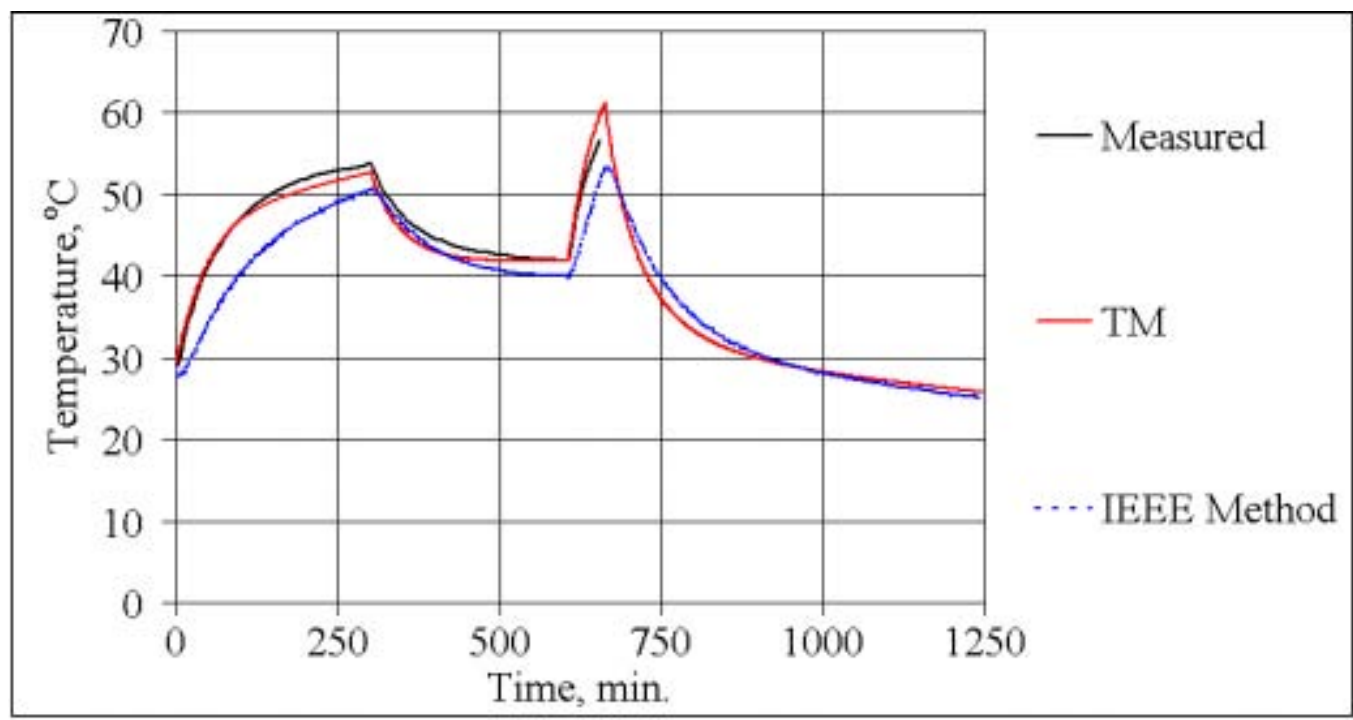

Figure 6: The top Oil temperature of 605 MVA OFAF cooled transformer

The data values of time and temperature as of ref. [21] have also been shown in Figs.5, 6, 7 for the similar values of 400, 80 and 605 MVA ONAF cooling system. It could be seen from these Figs. 2, 3, 4 well match with results in Figs. 5, 6, 7 of ref. [21] and validates the proposed thermal model.

\section{Results and Discussions}

The thermal modelling is based on the heat transfer theory for the natural flow of oil around vertical, inclined and horizontal plates and cylinders[22].The experimental results of the authors [21-25] has also formed the basis of modelling. The top oil temperature model and related nonlinear resistances has been presented. The top oil model has been validated. Variations in oil viscosity and winding resistance have been taken into account. The top oil temperature in the tank have been taken as a reference temperature for the oil viscosity evaluation. The results plotted by the proposed have been represented in Figs. 2,3,4 agree with the measured and the worked out values for the top oil temperature model . Fig.2 shows that top oil temperature increases rapidly after 10 hours for 400 MVA
ONAF cooling.It is also visible from this figure that initial temperature rise with respect to time is not so rapid. Fig.3 shows that temperature rise of top oil has been limited to about $6^{0} \mathrm{C}$ only for 80 MVA ONAF cooling. From Fig. 4 it can be seen that the nature of top oil temperature rise for 605 MVA ONAF cooling is slightly different than that of 400 MVA ONAF cooling .However ,rapid temperature rise could be seen after 10 hours for 605 MVA ONAF cooling and also temperature rise for 40 MVA ONAF cooling after 10 hours was rapid.

\section{Conclusion}

On the basis of present work the following conclusions have been derived:

1) Thermal modelling of power transformer top oil for natural heat transfer and ONAF cooling has been made.

2) The proposed thermal modelling results have been compared with the available results under the same condition of the power transformer.

3) The proposed thermal model has been found to compare well with one available in the literature. 


\section{International Journal of Science and Research (IJSR) \\ ISSN (Online): 2319-7064}

Index Copernicus Value (2015): 78.96 | Impact Factor (2015): 6.391

4) The various output results from the proposed model have been found out and discussed.

5) The effect of temperature with respect to time has been found remarkably in the top oil of the transformer under ONAF cooling for variable values of its MVA.

6) The effect of temperature with respect to time on the physical properties of top oil has been shown which is remarkable.

7) The model is based on heat transfer theory, application of the lumped capacitance method, thermal electrical analogy and definition of non-linear resistance.

\section{Future Scope}

Working life cycle modeling of the transformer under various heating and cooling condition requires further research in the area.

\section{References}

[1] Gill,A.SM “ The Design of Trnasformer Oil” ,International Symposium on Electrical Insulation,Anacheim,CAUSA,April 2-5,2000.

[2] P.J. Burton and et.al., "Application of liquid Chromatography to the Analysis of Electrical Insulating Material,International Conference on Large High Voltagr Electric System,CIGRE Proceedings of the 1998 session ,Paper 15-08,PP.Paris,France, 28 August3,September 1988.

[3] P.Cygan,J.R.Laghari, “ Models for Insultion Aging Under Electrical and Thermal Multistresses, "IEEE Transactions on Eletrical Insulation,Vol.25,No.5 ,PP923-934October 1990.

[4] D.J.T. Hill,T.T.Le,Darveniza and T.K.Saha, "Investigation into Effective Methodsfor Assessing the Condition of Insulation in Aged Power Transformer "IEEE Transactions on Power Delivery ,Vol.1.No.4,October.1988.

[5] R.Malewski,B.Poulin, “ Impulse Testing of Power Transformer Using the Transformer Function Method,"IEEE Transactions on Power Delivery.Vol.3,No.2 ,April 1988.

[6] IS:335.The Indian Standard Code for Insulating Oil(Transformer Oil), 1993.

[7] Philip,P.K.,"Insulation Pressboard for Transformers" Electrical India,Vol. XIX,No.24,PP.5-13,Jan.1980.

[8] Still ,Alfred ,Siskind,S,Charles" Elements of Electrical Machine Design" New York, McGraw-Hill, 1954.

[9] Meador,J.RTemperture rise of Water cooled Transformer -AIEE Vol.65,PP-18-21,Jan.1946.

[10] Handbook for Electrical Engineers $16^{\text {th }}$ Edition, New York, McGraw-Hill, 2013.

[11]Say,M.G. "Performance and Design of A.C.Machines"Pitman Publishing Ltd.London, $3^{\text {rd }}$ Edition 2013

[12](IEC,1993) "IEC72-1 Power Transformers: Part 1: General, $3^{\text {rd. }}$ edition Geneva 20,Switzerland1993.
[13]Feng J.Q,Sun P.,Tangt W.H.,Buse D.P. et.al.," Implementation of Power Transformer Temperature MoniteringSystem"International conference onPower System Technology,2002, Proceeding Power Conference,Vol.3,October 12-13,PP-1980-1983,2002.

[14]Blume L.F. et.al.,"Transformer Engineering- $2^{\text {nd }}$ edition,John Wiley \&sons,Inc,New York, 1951.

[15]Chu D,Lux A, "On line monitering of power transformer and components: review of key parameters" Electrical Insulation Conference and Electrical Manufacturing \& Coil Winding Conference,1999.Proceeding,26-28 October 1999,pp.669-675.

[16] Aubin J and Langhame Y, "Effect of oil viscosity on transformer loading Capibality at low ambient temperatures", IEEE Transactions on Power Delivery, Vol.7, Issue2, PP.516-524, April 1992.

[17] Incropera F P and Dewitt D P, "Fundamentals of Heat and Mass Transfer", $4^{\text {th }}$ edition,John Wiley \& Sons.PP.886, 1996 .

[18] King W J, "The Basic Laws and Data of Heat Transmission" mechanical Engineering, March-August, PP.191, 1932.

[19] Rice W Chester," Free and Forced Convection of Heat in Gases and Liquids II", Physical Review, Vol.21, PP.1288, AIEE Trans.April 1923.

[20] Rice W Chester," Free and Forced Convection of Heat in Gases and Liquids II", Physical Review, Vol.21, PP.131, AEEE Trans.February 1924.

[21] Susa D ,Lehtonen M and Nordman H, “ Dynamic Thermal Modeling of Distribution Transformers" Transaction of Power Delivery, 2004.

[22] Emsley A M and Stevens G C," Review of Chemical indicators of degradation of cellulosic electrical paper insulation in oil-filled transformers,"IEEEProcSci.Technology, Vol.141, No.5, PP.324-334, September 1994.

[23] Rafsback N T, "Short time emergency overlapping of power transformers, bachelor Thesis" Power company,ABB.Vassa,2001.

[24] Susa D,Palola J, Lehtonen M and Hyvarinen M, “ Temperature Rises in an OFAF Transformers at OFAN cooling mode in Service," Transaction on Power Delivery, December 2004.

[25] Susa D ,Lehtonen M and Nordman H, “ Dynamic Thermal Modeling of Power Transformers" IEEE Transactions on Power Delivery,Vol.20,Issue 1,PP.197204,January 2005.

\section{Author Profile}

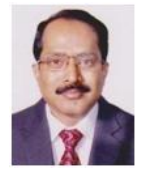

Dr. Ajoy Kumar completed his Bachelors and Masters in Engineering at B.I.T Sindri, and Ph.D at N.I.T. Jamshedpur. He is currently working as Principal at Chhatrapati Shivaji Maharaj Institute of Technology Panvel, University of Mumbai. 